\title{
MEMORIAL DE JUAN DE BORGOÑA SOBRE LA DECORACIÓN DEL CLAUSTRO DE LA CATEDRAL DE TOLEDO (1498 (?)
}

En 1650 se inició en el seno de la Universidad de Alcalá la segunda parte del proceso por el cual se intentaba conseguir la beatificación del Cardenal Cisneros. El 19 de julio de ese año, un franciscano muy activo y relacionado con la Universidad en tanto que familia de los escribanos contadores de la institución y antiguo alumno en sus aulas, fr. Pedro de Quintanilla, se ofrecía a hacerse cargo de las actuaciones de dicho proceso, lo que le llevó a desplazarse a la corte papal poco tiempo después ${ }^{1}$. En su estancia romana, además de otras muchas tareas que no nos interesan aquí, Quintanilla redactó la que se constituyó como la más apasionada biografía -diríamos hagiografía, dado que se redactó y publicó para hacer santo a Cisneros, con ribetes de ese género literarioescrita sobre fr. Francisco Ximénez de Cisneros ${ }^{2}$. Se trata de una obra completa y documentada, a veces erudita, a veces descuidada y, desde luego, fruto de muchos años de devoto trabajo de fr. Pedro. Era la segunda biografía sobre el prelado toledano. Con posterioridad a la edición y diversos avatares, el inquieto fraile regresó a Castilla donde, por cierto, además de continuar con sus desvelos en orden a elevar a los altares a su adorado Cisneros, continuó su labor recopiladora de materiales biográficos sobre el Cardenal, según parece habiendo aprendido en Roma el valor fundamental de los documentos para sus fines beatificadores ${ }^{3}$.

El resultado de sus investigaciones cristalizó en varios volúmenes de documentos, tanto originales como copias, relacionados con Ximénez de Cisneros, sus hechos y virtudes, algunos de ellos muy curiosos y relacionados con sus fundaciones y encargos arquitectónicos y artísticos, entre otros. Quintanilla depositó dichos volúmenes, junto con una gran cantidad de material relacionado con la causa de beatificación cisneriana, en el archivo de la Universidad de Alcalá. Dicho archivo, al extinguirse la institución, pasó a la Universidad Central de Madrid y, después, al Archivo Histórico Nacional, sección Universidades, no sin que algunos de sus fondos -entre ellos los de nuestro fraile- se conservasen algún tiempo en la Complutense madrileña.

Los volúmenes recogidos por Quintanilla forman un interesante apartado dentro de la sección de Universidades del Archivo Histórico Nacional. Inconfundibles por su contenido extraño a lo puramente universitario, aunque claramente vinculado a Cisneros, aún se encuentran clasificados como "antiguos tomos de documentos varios y antiguos, Universidad Complutense de Madrid". La mayoría de los documentos de la colección relacionados con el arte patrocinado por el prelado toledano ya han sido publicados.

Entre dichos papeles, concretamente conservado en el tomo 5 del conjunto documental, tenemos un documento, inédito por lo que sabemos, al parecer referido a intervenciones pictóricas de diversa índole realizadas en el claustro de la catedral de Toledo bajo el arzobispado de Cisneros, que Juan de Borgoña tasó o valoró -no queda claro si participó en ellas-. Aunque no da demasiadas

\footnotetext{
${ }^{1}$ Sobre el proceso de beatificación de Cisneros véase, entre otros, Castellanos De LosadA, B. S. Biografía de Don Fr. Francisco Ximénez de Cisneros, $2^{\mathrm{a}}$ ed., Madrid, 1868; Fuente, Vicente de la, Historia Eclesiástica de España, Madrid, 1874, tomo V, y en Historia de las Universidades, Colegios y demás establecimientos de enseñanza en Espa$\tilde{n} a$, Madrid, 1884-89, 4 vols; Pou Y MARTí, J. M. "Proceso de beatificación del Cardenal Cisneros", Archivo Ibero-Americano, tomo XVII, no. XLIX, 1922, pp. 5-28; Fernández De Retana, L. Cisneros y su siglo. Estudio histórico de la vida y actuación pública del Cardenal D. Fr. Francisco Ximénez de Cisneros, Madrid, 1930, tomo II, p. 524-538; RodRíGUEZ-MoÑIno SoRiano, R. El Cardenal Cisneros y la España del siglo XVII, Valencia, 1978; GonZÁLez Ramos, R. "El mecenazgo artístico de la Universidad de Alcalá en la Roma del Barroco (siglo XVII)", Madrid, Revista de Arte, Geografía e Historia, $\mathrm{n}^{\circ} .5$, 2002, pp. 247-291.

2 Quintanilla Y Mendoza, P. de. Archetypo de Virtudes, Espexo de Prelados. El venerable padre y siervo de Dios F. Francisco Ximenez de Cisneros, Palermo, Nicolás Bua, 1653.

${ }^{3}$ Sobre esta cuestión véase Meseguer FernándeZ, J. "Memoriales y cuestionarios del P. P. Pedro de Quintanilla sobre Cisneros", Archivo Ibero-Americano, tomo XXXVII, 1977, p. 155 y ss.
} 
noticias para mejorar nuestra comprensión del perdido conjunto pictórico de dicha parte de la Primada, creemos que debemos dar a conocer el documento, con sus limitaciones, para contribuir en lo posible al conocimiento de la vida y las actividades de tan relevante pintor. En primer lugar, el documento consta de un memorial rubricado por el propio Juan de Borgoña, en el que se evalúan los precios de las pinturas de índole puramente decorativo que se realizaban en "el jardín aposentamiento de Su Señoría en Toledo". A este memorial se une otro, más breve, que se refiere a otras pinturas -"que yo añadi allende lo suso dicho"-, que se habían de pintar en el oratorio, en el cenador del jardín y en la escalera principal de palacio.

Lamentablemente, no sabemos de dónde sacó el padre fr Pedro de Quintanilla este documento original -con letra de finales del siglo XV-, que no está fechado en ninguna de sus dos partes (¿quizás del archivo de la Catedral de Toledo, cuando estuvo allí indagando, en 1662?)4. Este inconveniente podría considerarse solventado -aunque en mi opinión es arriesgado fiarse- gracias a la anotación de su puño y letra, de 1681, que, como en otros documentos de la citada colección, el mismo Quintanilla añadió en la parte superior. Ese escueto añadido señala, entre otras cosas, que se trataba de un documento de 1498 referido a las pinturas que Cisneros hizo ejecutar en " $e l$ Claustro y jardín y otras partes de la Jglesia maior de Toledo"5.

\section{TRANSCRIPCIÓN:}

[Letra del padre Quintanilla]

Año de 1498 i otras partes

Pinturas que el Santo hizo pintar en el Claustro y jardin i otras partes de la Jglesia maior de Toledo, al fresco, a uso de Roma, en las paredes de dicho Claustro que oy se duran año de 1681. todas las del Claustro vajo i alto, se pintaron a su Costa, y mas siendo solo Arçobispo, i otras ya cardenal Consta tambien de sus Armas que se allan en ellas, que son las que usaba siendo Arçobispo, y siendo Cardenal, de la descension de $N^{a}$. Sa. la Virgen Maria a dar la Casulla a S. Ildefonso, con su capelo, y Borlas; que la $S^{t a}$. Jglesia de Toledo no las pone, sino en medio de un Feston, sin Capelo; ni borlas

[mismo folio, original] memorial de lo q se ha pintado en el jardin aposentamj ${ }^{o}$ de Su $S^{a}$. en $t^{o}$ y lo q costo [mismo folio, original, distinta letra, escrito del revés] memorial de lo q se ha de pintar en el jardin e aposentami ${ }^{\circ}$ St. $\left(\mathrm{f}^{\mathrm{o}} .52 \mathrm{v}^{\mathrm{o}}\right)$ - prymeramente en la capilla a de ser pintado las chillas de su Romano sus colores Repartydas de azul e carmyn e los maderos sus papos e costados de su Romano con sus chillas con al derredor su letrero de letras francesas meresce de pintar myll y quynientos mrs

- en el corredor luego salyendo de la capylla asy mesmo sus chyllas e Syntas de su Romano e los maderos los costados de colores e los papos de su Romano con sus colores Reptydos e fynas meresce de pintar con su letrero e cosa de anbas las partes pintado y el ala q buela fuera conforme al otro dos myll mrs

- mas una quadra luego salyendo del corredor al sur la pintura conforme al dicho corredor merece de pyntar myll y ochocientos mrs

\footnotetext{
4 Juan MESEGUER FERNÁNDEZ, Art. cit., p. 156.

5 Transcrito recientemente por MARÍAs, F. y PEREDA ESPESO, F. "Pedro Berruguete en Toledo ¿éxito o fracaso de un pintor?”, en Pedro Berruguete y su entorno. Simposium Internacional, Palencia, 2003, Palencia, 2004, p. 164, nota.
} 
- mas otra quadra grande con sus cosas papos e costados con sus alyscas del Romano e maderos los papos del Romano e costados de vermellon e chyllas y syntas de su Romano con sus colores byen Reparydos con sus cabygas con lo q ordenare su mersed asy mesmo su letrero esta quadra de esta manera pintado meresce tres myll y quynyentos mrs

- mas la pyesa questa de armadura questa ansyma de los artesones pintadas sus chyllas de unos candeles de largo a largo fasta el almysate y el almysate conforme con lotro e los maderos q se plastesan los vyejos q quedan yguales como los otros e sean pyntados los papos de Romano e costados colorados e tavyen de las armas de su señorya con su letrero a la redonda merese esta piesa de pyntar dos myll dosyentos mrs

- mas en la quadra de los artesones ovyere de aver en cada arteson un floron de bulto dorado e su canpo asul con una moldura de alderredor del floron: pero sy Vtra mers ${ }^{d}$ manda q se pynte como esta agora en los artesones de pintura de su Romano Repartydo uno de Una color e otro de otra y el papo de los artesones un lado q ara tal la obra e los costados de su romano de sus colores fynas e mas el letrero todo alderredor merese de pyntar cyen Reales $\left(\mathrm{f}^{\mathrm{o}} .53 \mathrm{r}^{\mathrm{o}}\right)$

- mas otra quadra grande q myre sobre el jardyn del tamaño como la grande de arryba y de la mesma suerte e del mesmo presyo que es tres myll quynientos mrs

- mas otra quadra bacha sobre el jardyn del tamaño de la de arryba y del mesmo presyo e de la mesma pyntura por q es todo de una mesma armadura el presyo es myll e ocho cyentos mrs

de toda esta obra me a de dar vtra mers ${ }^{d}$ madera para los andamyos e quyen los pago los dhos los adamyos

esto es lo q yo Ju de borgoña dygo q merese de pyntar para q vaya bueno e no merese un mrs menos

Juan de Vorgoña (rubricado)

Jhs

-lo q yo añadj allend de los Suso dho es lo Sige.

-en el oratorio Se han de pintar las paredes de Siertas Verduras y arboles y tiestos de clavelljnas e de yervas y sus arcos y sus pilares y entavlamjos

- mas en el çenador del jardin Se han de pintar las paredes de sus Verduras y arvoles y aves y sus tiestos y yervas y sus pilares y entavlamj ${ }^{\text {s y }}$ la madera del corredor q esta enzima desto ha de ser pintada y formar a lo de arriba deste mismo corredor

-yten se ha de pintar en el escalera prinçipal de los palaçios [...] de unas Ruedas de prieto y blanco con unos cordones de San fran ${ }^{c o}$ [...] q orlen alderredor por los Redondos todo lo de arriba y esto a mandado hazer por xvijU_"6.

El documento, sin tener en cuenta el añadido de Quintanilla, no sólo no nos aporta cronologías, sino que tampoco es muy explícito en cuanto a dónde se encontraban dichas estancias, salas, capilla o jardín -no digamos palacio-. Únicamente se hace referencia, en el encabezamiento, a que dichas pinturas se habían realizado o se habían de realizar (se estaría en pleno trabajo) en el jardín aposentamiento de Cisneros en Toledo.

Es hecho conocido el empeño de Cisneros en hacer que los canónigos toledanos hiciesen vida regular claustral. También sabemos por Blas Ortiz, como señalan Marías y Pereda, que en época de Cisneros se construyó un palacio real en el ámbito del piso superior del claustro de la

\footnotetext{
${ }^{6}$ Archivo Histórico Nacional (Madrid), Sección Universidades, legajo 756 (antiguo Tomo 5, Documentos varios y antiguos. Universidad Complutense de Madrid.), folio $52 \mathrm{r}^{\mathrm{o}} \mathrm{y}$ ss.
} 
catedral Primada, con obras que se documentan entre 1497 y 1500, en el que se constata había sala grande artesonada, diversas cámaras -pintadas desde 1499 por Juan de Borgoña y sus colaboradores- y unos aposentos desde los que Isabel la Católica podía asistir a misa anticipándose a la disposición de los de su nieto en El Escorial. Además, una escalera claustral de caja abierta se realizó en el ángulo noroeste del claustro, para dar servicio tanto a los canónigos como a la reina y su entorno ${ }^{7}$.

El documento que damos a conocer hace referencia a diversas estancias, que podrían ser las aludidas: capilla, cuadra saliendo del corredor sur, cuadra grande, pieza de armadura de artesones, cuadra grande sobre el jardín y, en un segundo texto, oratorio, cenador del jardín y escalera principal de los palacios. Probablemente se nos esté indicando que la capilla de Tenorio (en la panda del claustro), las salas de todo el lateral oriental del claustro y la escalera estaban en pleno proceso de decoración a base de dar colorido con motivos epigráficos y "al romano" los artesonados (fundamentalmente), para lo que eran necesarias las maderas para andamios de los que habla Borgoña. La pieza con armadura de artesones requería, además, la elección entre dos tipos de policromía. Los artesones llevarían un florón dorado en medio, y los "costados" las armas de Cisneros. Pero lo que más llama la atención es lo poco común de los motivos decorativos que Borgoña proponía añadir: en las paredes del oratorio, nada menos que "ciertas verduras y árboles y tiestos de clavellinas e de yervas", con pilares, arcos y entablamentos. Estos motivos, junto con los que proponía para el cenador, que incluían aves, nos hablan de una decoración de fingido fondo paisajístico-ajardinado enmarcado por arquitecturas también fingidas, que probablemente es un antecedente perdido de lo que años después se haría en la antesala capitular, el tantas veces ponderado remedo de "studiolo" renacentista de la catedral de Toledo.

ROBERTO GONZÁLEZ RAMOS UNIVERSIDAD DE CÓRDOBA

\footnotetext{
${ }^{7}$ Marías, F. y Pereda Espeso, F. Ob. cit., pp. 152-153. La referencia a Blas Ortiz: GonZálvez Ruiz, R. y Pereda EsPeso, F. La Catedral de Toledo 1549 según el Doctor Blas Ortiz, Toledo, 1999, p. 270.
} 